
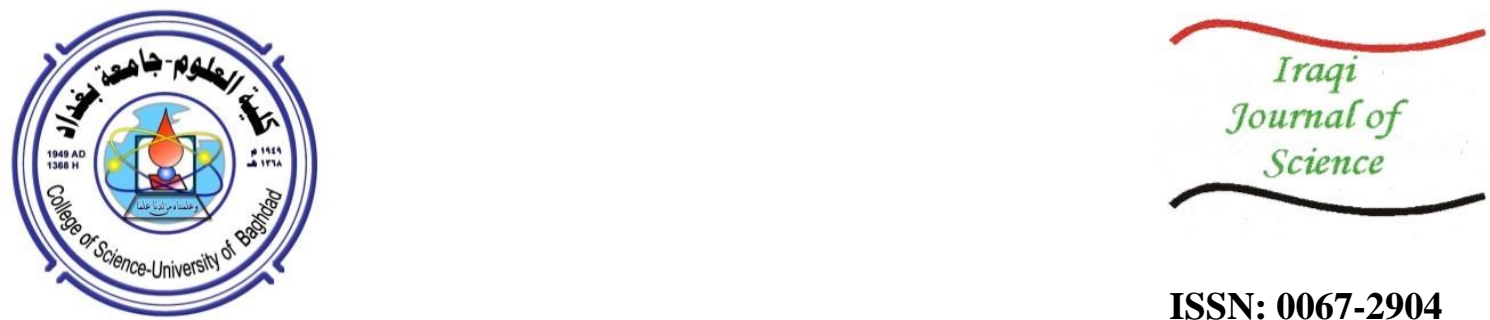

ISSN: 0067-2904

\title{
Determination of some virulence factors of Citrobacter freundii isolated from Iraqi patients
}

\author{
Asmaa Easa Mahmood*, Amidah Ali Atyah \\ Department of pathological analysis, Faculty of Applied Sciences, University of Samarra \\ Received: 2/9/2020 \\ Accepted: 20/11/2020
}

\begin{abstract}
This study included the isolation and identification of Citrobacter freundii from 220 samples collected from inpatients and outpatients suffering from urinary tract infection (UTI) and identified at the laboratory of the General Samarra Hospital in Samarra City, Iraq. The study was conducted to investigate some of the virulence factors produced by $C$. freundii. The results showed that 67 isolates were belonging to the $C$. freundii, with a rate of $30.45 \%$. Twenty eight samples were from inpatients (41.8\%) and 39 samples were from outpatients. The bacterial identification was based on cultural and biochemical tests and confirmed by using VITEK2 compact system. Virulence factor results showed that all isolates were not blood hydrolyzing whereas they produced protease. Seven isolates (10.4\%) produced biofilm, five from inpatients and two from outpatients, at rates of $17.8 \%$ and $5.1 \%$, respectively. The results showed that 17 (25.4\%) of the pathogenic isolates were $\beta$-lactamase producers, as determined by the iodometric method, twelve of them (17.9\%) were from inpatients and 5 (7.5\%) from outpatients. Four isolates of $C$. freundii produced Extended Spectrum Beta-lactamase (ES $\beta \mathrm{L}$ ) enzymes, three from inpatients and one from outpatients, with ratios of $4.5 \%$ and $1.4 \%$, respectively. Also, the via $B$ gene, which is responsible for virulence factors, was investigated using PCR. The results showed that 12 isolates from inpatients and 4 isolates from outpatients were harboring this gene. The antimicrobial susceptibility testing by Kirby-Bauer's method showed that all isolates that produced $\beta$-lactamase were resistant to antibiotics.
\end{abstract}

Key words: $C$. freundii, virulence factors, Biofilm, $\beta$-lactamase, ES $\beta$ L, PCR.

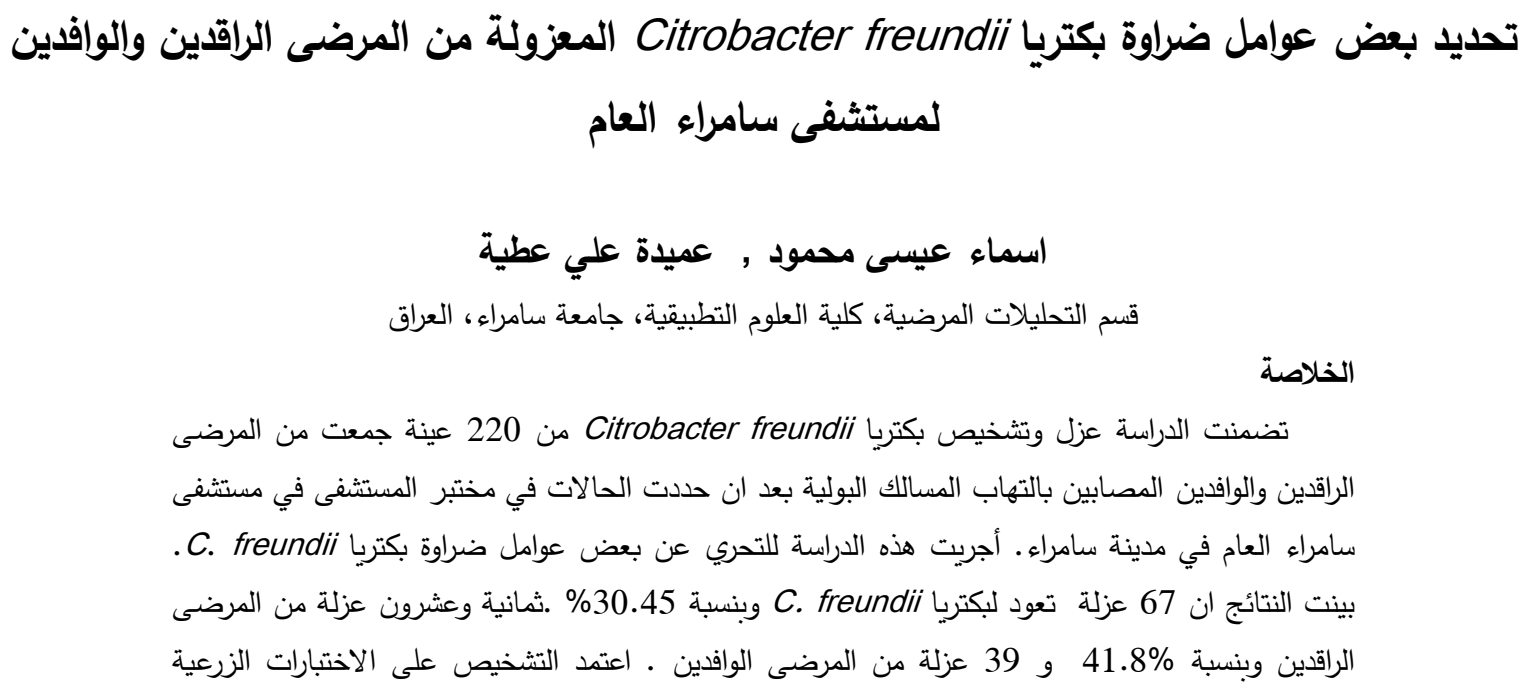




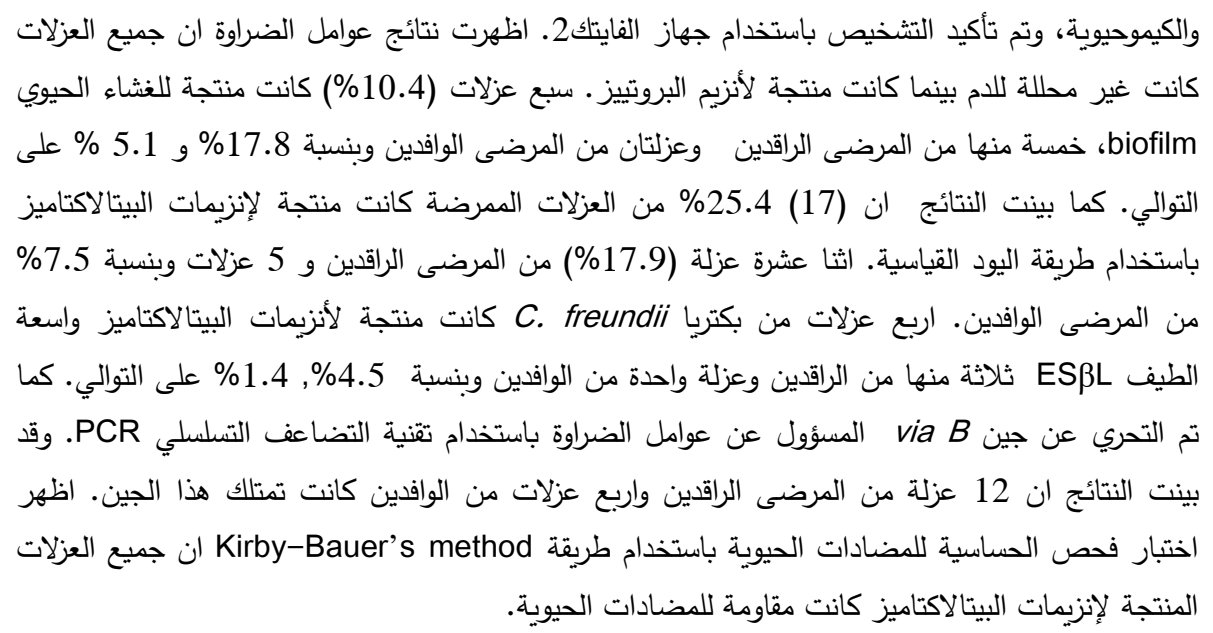

\section{Introduction}

Citrobacter freundii is a Gram negative, cocobacilli, lactose fermenter, facultative anaerobic member of the enterobacteriaceae family, which may be found in water, soil and in the gastrointestinal tracts of humans and animals. C. freundii causes urinary tract infections, wound infections, severe diarrhea, pneumonia, neonatal meningitis and brain abscesses in humans, especially in immunocompromised hosts [1]. C. freundii is considered as a major cause of nosocomial infections, characterized by inducible resistance mediated by the chromosomal AmpC $\beta$-lactamase [2]. Overtime, $C$. freundii isolated from hospitals patients suffering from urinary tract infection becomes more resistant to different antibiotics like beta-lactamase, third generation cephalosporins and aminoglycosides [3]. C. freundii has several virulence factors which are considered as means used by pathogenic microorganisms to express their pathogenicity and promote their survival in the hosts. Those virulence factors are closely related to the disease and can be elicited during antimicrobial therapy [4]. Virulence factors, including proteolysis, hemolysis and biofilm formation, have also been previously observed [5]. For example, diarrheagenic biofilm formation was discovered in C. freundii [6]. The diseases caused by $C$. freundii can be either community acquired or nosocomial infections [7]. Studies of $C$. freundii demonstrated their potential risks due to the production of some virulence factors which contain the genes of resistance and pathogenicity that convert these bacteria into a more deadly and resistant organism [8]. Therefore, the present study aimed to investigate the different percentages of the virulence factors of $C$. freundii isolated from inpatients and outpatients suffering from UTI.

\section{Materials and methods}

\section{Isolation and diagnosis of bacterial isolates}

All pathogenic bacteria were obtained from the inpatients and outpatients in the General Samarra Hospital. The bacterial isolates were cultivated on selective and differential media (MacConkey agar, Blood agar, Mannitol salt agar) in the laboratory, where they were stained by Gram stain and subjected to some biochemical tests [9]. To confirm the identification of bacterial isolates, VITEK2 compact system was performed. All the collected isolates were isolated from urinary tract infections.

\section{Virulence factor tests}

\section{Hemolytic activity}

Plate method was used to detect the hemolysis activity . Each isolate was streaked onto 5\% sheep blood agar (Himedia, India) and incubated at $37^{\circ} \mathrm{C}$ for 24 hours. Isolates exhibiting hemolytic zones surrounding the growth were considered positive [10].

\section{Proteolysis test}

To detect the proteolysis of bacterial isolates, bacterial suspension was prepared by culturing a single colony of each isolate in $5 \mathrm{ml}$ nutrient broth and incubated at $37^{\circ} \mathrm{C}$ for 18 hours. $100 \mu \mathrm{lof}$ each suspension was transported to the prepared wells in skimmed milk agar plates. The plates were incubated at $37^{\circ} \mathrm{C}$ for $24-48$ hours. The diameter of lysis was measured [11].

\section{Biofilm production}

Formation of biofilm was tested using Congo red agar (CRA) plates. CRA plates were inoculated with tested bacteria and incubated at $37^{\circ} \mathrm{C}$ for 24 to 48 hours aerobically. Black colonies with a dry 
crystalline consistency indicated biofilm production [12].

\section{$\beta$-lactamase test}

The standard iodine method was used to detect the $\beta$-lactamase production. Overnight bacterial cultures were prepared and the bacterial colonies were transferred to $100 \mu \mathrm{l}$ of penicillin G solution, and the tubes were incubated for 30 minutes at $37^{\circ} \mathrm{C}$. Fifty $\mu$ l of starch solution were added to each tube and mixed well. To each tube, $20 \mu \mathrm{l}$ of iodine solution were added. The result was considered as positive upon the rapid color change from blue to white, i.e. within 5 minutes after adding the iodine reagent [13].

\section{Extended spectrum $\beta$-lactamase test}

All isolates were examined by disc approximation tests for identifying the ability of bacterial isolates to produce ES $\beta \mathrm{L}$. Increasing the inhibition zone between the disc of Augmentin and the discs of Piperacillin, cefotaxime, and Ceftriaxone indicates positive reactions [14].

\section{Polymerase Chain Reaction}

PCR technique is used to investigate the genes responsible for bacterial virulence factors. The primer pair VIAB-1 from 5867 bp to 5888 bp (TGTCGAGCAGATGGATGAGCAT) and VIAB-2 from $6362 \mathrm{bp}$ to $6383 \mathrm{bp}$ (ACGGCTGAAGGT TACGGACCGA) was used. This primer pair will amplify and produce a double-stranded fragment of $515 \mathrm{bp}$. The primers were prepared according to the instructions of the manufacturer company (Microgen company). The mixture of PCR was set up in $25 \mu \mathrm{l}$ as a final volume that contains $5 \mu \mathrm{l}$ of PCR green master mix $(1 \mathrm{X} / \mu \mathrm{l})$ and $1 \mu \mathrm{l}(10 \mathrm{pmol})$ of each of forward and reverse primers. DNA template $(1.5 \mu \mathrm{l}$ in concentration of $50 \mathrm{ng} / \mu \mathrm{l})$ and distilled water $(16.5 \mu \mathrm{l})$ were added to form the final volume. The tubes containing the samples were placed in thermocycler device to perform PCR according to the appropriate amplification program for each primer, as described previously [15].

\section{Antibiotic Susceptibility Test}

The disc diffusion method was used to detect antibiotic sensitivity of the isolates using the KirbyBauer method cited by an earlier work [16]. The results were compared with the standard diameter of inhibition zones for each antibiotic [17]. Eighteen antibiotic discs were used in this research (Bioanalyse/ India).

\section{Results and Discussion}

\section{Isolation of bacterial samples}

Two hundred twenty samples were collected from the inpatients and outpatients suffering from UTIs. The results showed that 67 samples belonged to $C$. freundii, 28 (41.8\%) from inpatients and 39 (58.2\%) from outpatients, as shown in Table-1. The results of this study are inconsistent with the findings of a previous work [18].

Table 1-Bacterial numeration rates of $C$. freundii

\begin{tabular}{|c|c|c|c|c|}
\hline \multirow{2}{*}{ Groups } & \multicolumn{2}{|c|}{ Samples } & \multicolumn{2}{c|}{ C. freundii } \\
\cline { 2 - 5 } & No. & $\%$ & No. & $\%$ \\
\hline Inpatients & 70 & 31.81 & 28 & $41.8 \%$ \\
\hline Outpatients & 150 & 68.19 & 39 & $58.2 \%$ \\
\hline Total & 220 & 100 & 67 & $100 \%$ \\
\hline
\end{tabular}

\section{Identification of bacterial isolates}

The results in Table- 2 show the outcomes of the cultural and biochemical tests that were performed on the isolates under study. These results are consistent with those of the approved diagnostic systems [9-11].

Table 2-Biochemical and morphological properties results of $C$. freundii

\begin{tabular}{|c|c|c|c|c|c|c|c|c|c|c|c|c|}
\hline \multirow{2}{*}{ 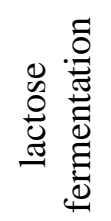 } & \multirow{2}{*}{ 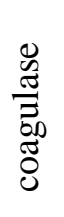 } & \multicolumn{4}{|c|}{ IMVIC } & \multirow{2}{*}{ 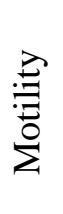 } & \multirow{2}{*}{$\begin{array}{l}\frac{n}{0} \\
\frac{\lambda}{2} \\
\stackrel{0}{0} \\
\frac{0}{0} \\
\end{array}$} & \multirow{2}{*}{ 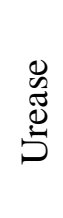 } & \multirow{2}{*}{ 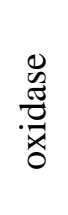 } & \multirow{2}{*}{ 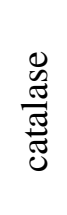 } & \multirow{2}{*}{ 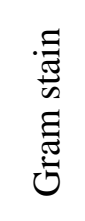 } & \multirow{2}{*}{ 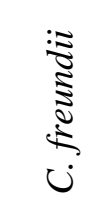 } \\
\hline & & $\mathrm{C}$ & VP & MR & $\begin{array}{l}\text { IN } \\
\text { D }\end{array}$ & & & & & & & \\
\hline+ & - & + & - & + & - & + & - & V & - & + & $\mathrm{G}^{-\mathrm{ve}}$ & Tests \\
\hline
\end{tabular}


Gve: Gram negative bacteria, IND: indole, MR: methyl red, VP: Voges proskaur, C: Citrate utilization, V: variable

\section{Virulence factor tests}

The results of the hemolysis pattern showed no hemolysin activity on sheep blood agar plates of all the bacterial isolates under study. The results are consistent with those found a previous study [19].

In contrast, all isolates showed the ability to produce protease enzyme on skimmed milk agar. This enzyme is one of the important virulence factors that hydrolyzes peptide bonds and thus helps bacteria to invade another tissue [20]. The results disagree with those reported earlier [19], which found that only $36 \%$ of $C$. freundii were protease producers.

Seventeen isolates were shown to produce $\beta$-lactamase, $17.9 \%$ from inpatients and $7.5 \%$ from outpatients, as listed in Table-4. The results disagree with those of other authors [21] who reported that all Ctrobacter species were $\beta$-lactamase producers.

The results listed in Table-3 show the ability of 4 isolates of $C$. freundii, out of 67 isolates, to produce ES $\beta$ L enzyme, 3 from inpatient (4.5\%) and one from outpatient. This result is similar to that of another investigation [22], which found that $2.6 \%$ of $C$. freundii were ES $\beta$ L producers. Whereas another work [23] reported that $63.3 \%$ of the isolates were producers of this enzyme.

Table 3-Percentage of production of $\beta$-lactamase and Extended Spectrum Beta-lactamase from isolates of C. freundii

\begin{tabular}{|c|c|c|c|c|c|}
\hline Groups & No. & $\beta$-lactamase + & $-\beta$-lactamase & ES $\beta \mathrm{L}+$ & ES $\beta \mathrm{L}-$ \\
\hline Inpatients & 28 & $12(17.9 \%)$ & $16(23.9 \%)$ & $3(4.5 \%)$ & $25(37.4 \%)$ \\
\hline Outpatients & 39 & $5(7.5 \%)$ & $34(50.7 \%)$ & $1(1.4 \%)$ & $38(56.7 \%)$ \\
\hline Total & 67 & $17(25.4 \%)$ & $50(74.6 \%)$ & $4(5.9 \%)$ & $63(94.1 \%)$ \\
\hline
\end{tabular}

Table-4 reveals the bacterial numeration rate of biofilm production. The results showed the ability of some $C$. freundii isolates to produce the biofilm on CRA by giving black colonies, as shown in Figure -1 . The biofilm helps the bacteria to survive in extreme conditions within the host and is responsible for chronic and acute infections, including endocarditis, cystic fibrosis, otitis media, medical devicerelated injuries, and catheter infections [24].

Biofilm formation by nosocomial pathogenic bacteria leads to increased resistance against antibiotics by expanding mutation rates and exchanging genes responsible of bacterial resistance to antibiotics [25]. Previous studies demonstrated biofilm formation in patients suffering from bacterial infections [26].

A

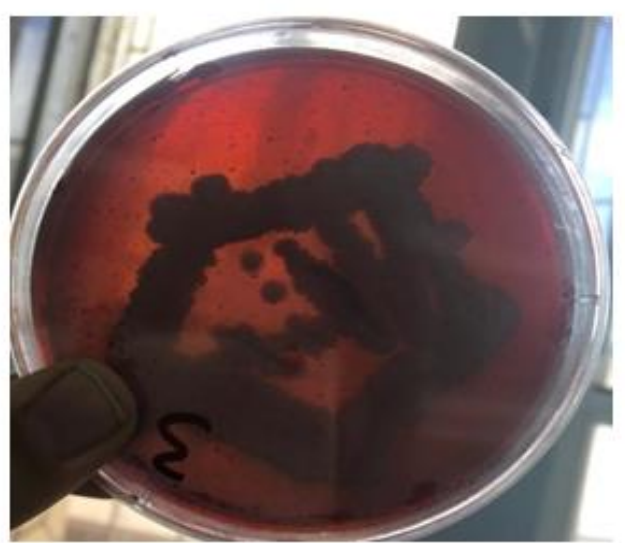

B

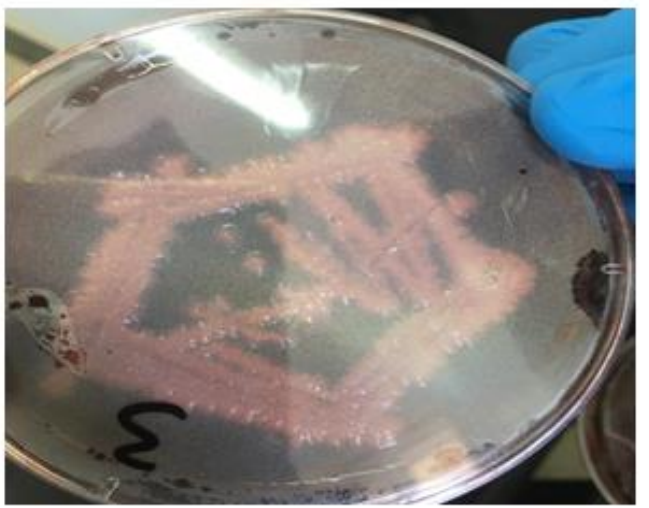

Figure 1-A- Positive for biofilm production, B- Negative for biofilm production

Table 4-Percentage of production of biofilm by $C$. freundii

\begin{tabular}{|c|c|c|c|}
\hline Groups & No. & biofilm + & -biofilm \\
\hline Inpatients & 28 & $5(7.5) \%$ & $23(34.4 \%)$ \\
\hline Outpatients & 39 & $2(2.9) \%$ & $37(55.2 \%)$ \\
\hline Total & 67 & $7(10.4) \%$ & $60(89.6 \%)$ \\
\hline
\end{tabular}

PCR Analysis of Virulence Genes 
The isolates of $C$. freundii were subjected to PCR analysis to determine the genes responsible for the production of these virulence factors. Sixty seven isolates of $C$. freundii were tested to investigate the presence of the via $\mathrm{B}$ gene. The results in Table- 5 show the presence of via $\mathrm{B}$ gene, determined by a molecular size of $515 \mathrm{bp}$, in 12 isolates from inpatients and 4 from outpatients, as also illustrated in Figure-2. The presence of via $B$ gene permits the bacteria to evade the innate immune system by expanding the host response during the infection [27]. C. freundii can acquire integrons, plasmids, or transposon containing resistance genes that confer this bacteria severe pathogenicity. There is also clear evidence of the presence of shiga like toxins in some strain of $C$. freundii [28]. This contrasts with a previous study which indicated that $C$. freundii isolated from animals contained no shiga like toxin genes [2].

Table 5-The presence of via $B$ gene in the isolates under study

\begin{tabular}{|l|l|l|l|}
\hline Groups & No. & via B gene + & via B gene - \\
\hline Inpatients & 28 & $12(17.9 \%)$ & $16(23.8 \%)$ \\
\hline Outpatients & 39 & $4(5.9 \%)$ & $35(52.2 \%)$ \\
\hline Total & 67 & $16(23.8 \%)$ & $51(76 \%)$ \\
\hline
\end{tabular}

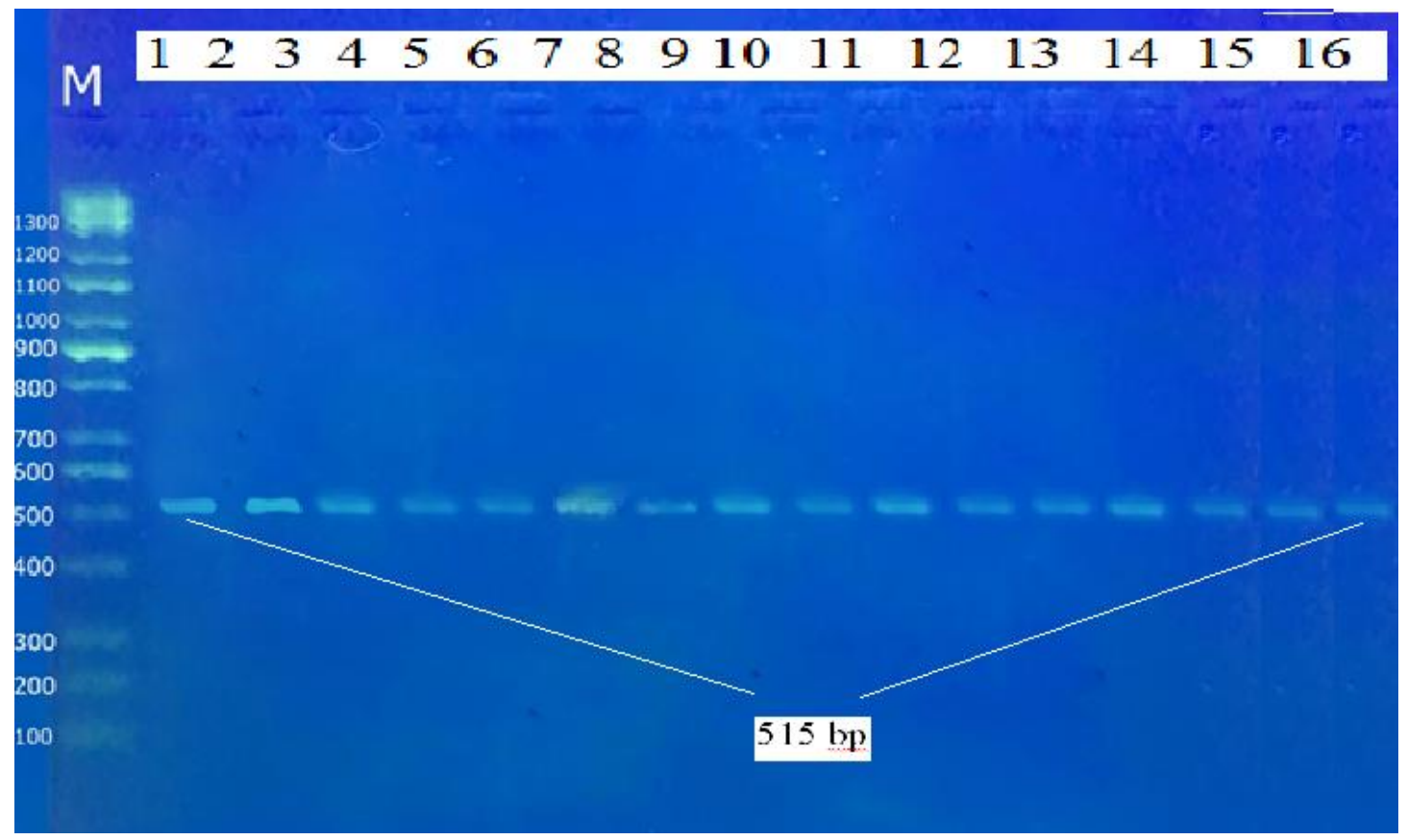

Figure 2- Gel electrophoresis profile of via $B$ gene amplicon encoding for virulence factors by $C$. freundii. Lane M: DNA ladder 100-1500 bp. Lanes 1-12 from inpatients and 13-16 from outpatients in 515 bp represent the presence of via $B$ gene on $2 \%$ agarose.

\section{Susceptibility of $C$. freundii to antibiotics}

The results of susceptibility test for antibiotics showed that the resistance values of $C$. freundii isolated from the inpatient to Imipenem, Augmentin and Levofloxacin were 7.1\%, $17.8 \%$ and 32\%, respectively. The results for the outpatient isolates were $0 \%, 2.5 \%, 46 \%, 12.8 \%, 2.5 \%$ and $25.6 \%$ resistance to Imipenem, Augmentin, ciprofloxacin, Norfloxacin, Levofloxacin and Amoxacillin, respectively. Table- 6 shows that most of the isolates were highly resistant to most of the antibiotics. Also the results showed that the samples isolated from inpatients were more resistance to antibiotics compared to those from the outpatient's isolates. The factors that lead to the emergence of acquired infections might include severe illnesses, pre-hospitalization, poor nutritional status, and excessive antibiotics use. The present study showed that the majority of bacterial isolates had a relatively high resistance to $\beta$-lactam antibiotics, such as the third generation of cephalosporins. While Imipenem, a group of Carbapenems, showed a high effectiveness against all bacterial isolates. Resistance to broadspectrum cephalosporins (third and fourth generation) is achieved through diminishing permeability through the outer membrane, higher production of AmpC $\beta$-lactamase enzymes, acquisition of 
plasmids, or the combination of these factors together. The results of the present study are in accordance to those of a previous study [29], which showed the susceptibility of some Gram negative bacteria to 24 antibiotics. The authors found that most of the isolates were highly resistant to most of the antibiotics, which may be due to the production of $\beta$-lactamase. Also, the results of the present study are similar to those obtained by other authors [30], who found that most of bacterial pathogens isolated from UTI were sensitive to Imipenem.

Table 6-Resistance of $C$. freundii to antibiotics

\begin{tabular}{|c|c|c|}
\hline Samples & Inpatients & Outpatients \\
Antibiotics & 28 & $18(46 . \%)$ \\
\hline Ciprofloxacin & $20(71.4 \%)$ & $35(89.7 \%)$ \\
\hline Piperacillin & $28(100 \%)$ & $33(84.6 \%)$ \\
\hline Amikacin & $18(64.3 \%)$ & $28(71.7 \%)$ \\
\hline Gentamicin & $22(78.5 \%)$ & $0(0 \%)$ \\
\hline Imipenem & $2(7.1 \%)$ & $39(100 \%)$ \\
\hline Ceftazidime & $28(100 \%)$ & $39(100 \%)$ \\
\hline Cefotaxime & $28(100 \%)$ & $6(2.5 \%)$ \\
\hline Levofloxacin & $9(32 \%)$ & $39(100 \%)$ \\
\hline Penicillin G & $28(100 \%)$ & $1(2.5 \%)$ \\
\hline Augmentin & $5(17.8 \%)$ & $35(89.7 \%)$ \\
\hline Carbenicillin & $24(85 \%)$ & $39(100 \%)$ \\
\hline Cefepime & $28(100 \%)$ & $39(100 \%)$ \\
\hline Cephalothin & $28(100 \%)$ & $39(100 \%)$ \\
\hline Ceftriaxon & $28(100 \%)$ & $39(100 \%)$ \\
\hline Ampicillin & $28(100 \%)$ & $5(12.8 \%)$ \\
\hline Norfloxacin & $23(82 \%)$ & $39(100 \%)$ \\
\hline Cefexime & $28(100 \%)$ & $10(25.6 \%)$ \\
\hline Amoxacillin & $22(78.5 \%)$ & \\
\hline & & \\
\hline & & \\
\hline
\end{tabular}

\section{Conclusions}

C. freundii that cause urinary tract infections have many virulence factors, as well as resistance to several antibiotics. The percentage of these factors and resistance is higher in inpatients than in outpatients, which indicates the seriousness of the nosocomial infections.

\section{Acknowledgements}

We would like to show our gratitude to the Department of Pathological Analyses/ College of Applied Sciences/ University of Samarra.

\section{References}

1. Liu, X., Huang, Y., Xu, X., Zhao, Y., Sun, Q., Zhang, Z., An, X. 2016. Complete genome sequence of multidrug-resistant Citrobacter freundii strain P10159, isolated from urine samples from a patient with esophageal carcinoma. Genome Announcements, 4(1): e01754-15. doi:10.1128/ genomeA.01754-15.

2. Bai, L., Xia, S., Lan, R., Liu, L., Ye, C., Wang, Y., and Bai, X. 2012. Isolation and characterization of cytotoxic, aggregative Citrobacter freundii. PLoS One, 7(3): e33054.

3. Akinbami, O. R., Olofinsae, S., and Ayeni, F. A. 2018. Prevalence of extended spectrum beta lactamase and plasmid mediated quinolone resistant genes in strains of Klebsiella pneumonia, Morganella morganii, Leclercia adecarboxylata and Citrobacter freundii isolated from poultry in South Western Nigeria. PeerJ 6:e5053; DOI 10.7717/peerj.5053

4. Choi, S. H., Lee, J. E., Park, S. J., Choi, S. H., Lee, S. O., Jeong, J. Y. and Kim, Y. S. 2008. Emergence of antibiotic resistance during therapy for infections caused by Enterobacteriaceae producing AmpC $\beta$-lactamase: implications for antibiotic use. Antimicrobial agents and chemotherapy, 52(3): 995-1000. 
5. Fakruddin, M., Rahaman, M. M., Ahmed, M. M., and Hoque, M. M. 2014. Antimicrobial resistance and virulence factors of enterobacteriaceae isolated from food samples of Bangladesh. International Journal of Microbiology and Immunology Research, 3(1): 12-18.

6. Pereira, A. L., Silva, T. N., Gomes, A. C., Araújo, A. C., and Giugliano, L. G. 2010. Diarrheaassociated biofilm formed by enteroaggregative Escherichia coli and aggregative Citrobacter freundii: a consortium mediated by putative F pili. BMC microbiology, 10(1): 57.

7. Thapa, B., Adhikari, P., Mahat, K., Chhetri, M. R., and Joshi, L. N. 2009. Multidrug-resistant nosocomial Citrobacter in a hospital in Kathmandu. Nepal Medical College Journal, 11(3): 195199.

8. Amaretti, A., Righini, L., Candeliere, F., Musmeci, E., Bonvicini, F., Gentilomi, G. A., and Raimondi, S. 2020. Antibiotic Resistance, Virulence Factors, Phenotyping, and Genotyping of Non-Escherichia coli Enterobacterales from the Gut Microbiota of Healthy Subjects. International journal of molecular sciences, 21(5): 1847.

9. Mahon, C., Manuselis, G., and Lehman, D. 2015. "Textbook of Diagnostic Microbiology". Elsevier 5rd ed. USA: Saunders Company, 868 p.

10. Cheesebrough, M. 2006. District laboratory practice in tropical countries. Part 2, second edition Cambridge University press, 35-70.

11. Josephine, A., Morello, P. A., and Mizel, G. H. E. 2003. Laboratory manual and workbook in microbiology applications to patient care. Edisi ke-7.

12. Mathur, T., Singhal, S. Khan, S., Upadhyay, D.J., Fatma, T., and Rattan, A. 2006. Detection of biofilm formation among the clinical isolates of Staphylococci: An evaluation of three different screening methods. Indian Journal of Medical Microbiology. 24(1): 25-29.

13. World Health Organization. 1978. Tachnique for the detection of ß-lactamase production strain of enterobacteriaceae.p 52-77

14. Poulou, A., Grivakou, E., Vrioni, G., Koumaki, V., Pittaras, T., Pournaras, S., and Tsakris, A. 2014. Modified CLSI extended-spectrum $\beta$-lactamase (ESBL) confirmatory test for phenotypic detection of ESBLs among Enterobacteriaceae producing various $\beta$-lactamases. Journal of clinical microbiology, 52(5): 1483-1489.

15. Lin, C., Chiu, C., Chu, C., Huang, Y., Lin, T., and Ou, J. T. 2007. A multiplex polymerase chain reaction method for rapid identification of Citrobacter freundii and Salmonella species, including Salmonella Typhi. Journal of Microbiology, Immunology and Infection, 40(3): 222-226.

16. Vandepitte, J., Verhaegen, J., Engbaek, K., Rohner, P., Piot, P., Heuck, C.C. 2003. "Basic Laboratory Procedures in Clinical Bacteriology". WHO. Geneva.

17. CLSI, C. 2014. Performance standards for antimicrobial susceptibility testing; twenty-fourth informational supplement. M100-S24 January.

18. Hammad, R. N., and Obaid, H. H. 2020. Assessment of Genotoxicity of Citrobacter freundii Bacteriocin on Bone Marrow Cells in Albino Mice. Iraqi Journal of Science, 999-1007.

19. Sabrina Hossain, S.H.M.P. Wimalasena and Gang-Joon Heo, 2017. Virulence factors and antimicrobial resistance pattern of Citrobacter freundii isolated from healthy pet turtles and their environment. Asian Journal of Animal and Veterinary Advances, 12: 10-16.

20. Miyoshi, S. I. 2013. Extracellular proteolytic enzymes produced by human pathogenic Vibrio species. Frontiers in microbiology, 4: 339.

21. Anjana, S., Varsha, S., and Arunima, S. 2015. Multiple Antibiotic Resistance profile of environmental Citrobacter isolates harboring virulent markers isolated from fresh water reverine environment of Narmada, India. International Journal, 3(6): 762-770.

22. Sang, Y., and Blecha, F. 2008. Antimicrobial peptides and bacteriocins: alternatives to traditional antibiotics. Animal Health Research Reviews, 9(2): 227-235.

23. Hayder, T., and Aljanaby, A. A. J. J. 2019. Antibiotics susceptibility patterns of Citrobacter freundii isolated from patients with urinary tract infection in Al-Najaf governorateIraq. International Journal of Research in Pharmaceutical Sciences, 10(2): 1481-1488.

24. Khan, F., Shukla, I., Rizvi, M., Mansoor, T. and Sharma, S. 2011 Detection of Biofilm Formation in Staphylococcus aureus. Does it have a role in Treatment of MRSA Infections. Trends in Medical Research, 6(2): 116-123. 
25. Niveditha, S., Pramodhini, S., Umadevi, S., Kumar, S., and Stephen, S. 2012. The isolation and the biofilm formation of uropathogens in the patients with catheter associated urinary tract infections (UTIs). Journal of clinical and diagnostic research: JCDR, 6(9): 1478.

26. Zogaj, X., W. Bokranz, M. Nimtz and U. Romling, 2003. Production of cellulose and curli fimbriae by members of the family Enterobacteriaceae isolated from the human gastrointestinal tract. Infection and Immunity, 71: 4151-4158.

27. Rondini, S., Micoli, F., Lanzilao, L., Pisoni, I., Di Cioccio, V., Saul, A. J., and Martin, L. B. 2012. Characterization of Citrobacter sp. line 328 as a source of Vi for a Vi-CRM 197 glycoconjugate vaccine against Salmonella Typhi. The Journal of Infection in Developing Countries, 6(11): 763773.

28. Schmidt, H. E. R. B. E. R. T., Montag, M. O. N. I. K. A., Bockemühl, J., Heesemann, J. U. R. G. E. N., and Karch, H. E. L. G. E. 1993. Shiga-like toxin II-related cytotoxins in Citrobacter freundii strains from humans and beef samples. Infection and immunity, 61(2): 534-543.

29. Daham, S. N., Abdullwahab, M. H., Mahmood, A. E., and Akram, E. 2018. Synthesis and Evaluation the Activity of 1, 3, 4-Thiadiazole Derivatives as Antibacterial Agent Against Uncommon Bacteria Causes of Urinary Tract Infections. Rafidain journal of science, 27(5EMicrobiology): 58-70.

30. Salman, S. B., and Al-Mathkhury, H. J. F. 2016. Molecular Detection of Klebsiella pneumoniae serotype K2 Isolated Clinically. Iraqi Journal of Science, 57(1A): 98-103. 